\title{
EVALUATION OF THE EFFECT OF CHOLECALCIFEROL AND CALCIUM ON A DELAYED DENTAL IMPLANT ON POST-MENOPAUSAL FEMALES
}

\author{
Engy M. Farid ${ }^{1} B D S$, Magda M. Saleh ${ }^{2} P h D$, Lydia N. Melek ${ }^{3} P h D$.
}

\begin{abstract}
INTRODUCTION: The replacement of the natural teeth has been the aim of mankind since ancient time. That's why we use dental implant and its osseointegration should be enhanced. By using Cholecalciferol and Calcium on postmenopausal females. OBJECTIVES: The aim of the study was to evaluate the effect of combination of cholecalciferol and calcium on delayed dental implants healing for postmenopausal females.

MATERIALS AND METHODS: A clinical and radiographical study was carried out on 14 postmenopausal female patients with age range from 40 to 60 years having missing maxillary anterior teeth. All the patients received the same implant system. The study group only received cholecalciferol and calcium for 8 months and the control group didn't receive thing. After placement all implants were evaluated clinically after 4 and 8 months (modified gingival index, papillary bleeding index, and degree of mobility) and radiographically after 4 and 8 months to evaluate marginal bone loss.

RESULTS The study group showed an increase in bone density. Group I(study): was better with a mean of (120.8 \pm 39.53 ) pixel while Group II(control): showed a mean of $(90.84 \pm 41.6)$ pixel the difference of the bone density between the two groups was statistically significant $(\mathrm{p}=0.008)$.

CONCLUSIONS: The implant placement in postmenopausal female patients may be successful. Cholecalciferol and calcium has systemic effects on accelerating bone formation around titanium implants.

KEYWORDS: Dental implant, Cholecalciferol, Calcium, Postmenopausal females, Osseointegration.

1- Bachelor of Dentistry, BDS, Faculty of Dentistry, 6October University, Cairo, Egypt.

2- Professor of Oral and Maxillofacial Surgery, BDS, MSc, PhD, Faculty of Dentistry, Alexandria University, Alexandria, Egypt.

3- Lecturer of Oral and Maxillofacial Surgery, BDS, MSc, PhD, Faculty of Dentistry, Alexandria University, Alexandria, Egypt.
\end{abstract}

\section{INTRODUCTION}

The replacement of missing teeth by means of endosseous dental implants has become an important part of dentistry. Over the last two decades, research has validated the success of osseointegrated implants as a viable replacement for partial and complete edentulous patients. Although techniques and materials have been developed which are capable of high degree of clinical success, the ultimate longterm success of implants is dependent upon the effort of both the patient and dentist in maintaining the health of periimplant tissue (1).

Delayed implant placement has several advantages. These include resolution of infection at the site and an increase in the area and volume of soft tissue for flap adaptation. The delayed method of implantation shows earlier and wide bone formation and less surrounding fibrous encapsulation. Their results indicate that the delayed technique can be an efficient method for establishing good bone binding $(2,3)$.

Various factors may enhance or inhibit implant osseointegration. Factors enhancing osseointegration include implant-related factors such as implant design and chemical composition, topography of the implant surface, material, shape, length, diameter, implant surface treatment and coatings (4), the status of the host bone bed and its intrinsic healing potential (5), the mechanical stability and loading conditions applied on the implant (6), the use of adjuvant treatments such as bone grafting, osteogenic biological coatings and biophysical stimulation( 7,8$)$ and pharmacological agents such as simvastatin and bisphosphonates (9,10). Supplementation with cholecalciferol (vitamin D3) is reported to show positive effects on bone mineral density $(11,12)$. In vivo experiments showed that vitamin D3 regulates intestinal calcium absorption and inhibits bone resorption independent of its calcium effect. In addition, vitamin D has been widely used for the prevention and treatment of osteoporosis $(13,14)$.

A study conducted in 2013 in the United Kingdom (15) looks at whether or not taking a vitamin $\mathrm{D}$ supplement made people's bones more dense and strong.

The following focus question was raised: "Can a combination of cholecalciferol and calcium decrease the risk factor of putting a dental implant for postmenopausal females?

The following study was conducted to evaluate the effect of Cholecalciferol /Calcium combination on the success of delayed dental implants on postmenopausal females.

\section{MATERIALS AND METHODS \\ I-Study design}

This study was a randomized clinical trial of 14 postmenopausal female patients with age range from 40 to 60 years having missing maxillary anterior teeth. The patients were selected from the outpatient clinic of The Oral and Maxillofacial Surgery Department, Faculty of Dentistry, Alexandria University.

The patients were randomly allocated:

Group A: (Study group) seven patient had missing maxillary anterior single rooted tooth, undergo placement of delayed dental implant and receivied Cholecalciferol and Calcium for 8 months.

Group B: (Control group) seven patient had missing maxillary anterior single rooted tooth; underwent placement 
of delayed dental implant and didn't receive anything. The participating patients in this study were chosen according to the following criteria:

\section{II-Inclusion criteria:}

Age range from 40-60 years, females, good oral hygiene, nonsmokers, normal blood calcium.

\section{III-Exclusion criteria:}

presence of infection, patient taking chemotherapy or radiotherapy, males, patient with renal disease, any parafunctional habits (bruxism, clenching), alcohol or drug abuse.

\section{IV- Informed consent:}

Informed consents were taken from all patients after explaining all the procedures to the patients including all benefits and side effects in simple and easy way, also the patients have the right for withdrawal at any time.

\section{Materials}

\section{I-Implant system}

Dio (US) System (66, Centum seo-ro, Haeundae-gu, Busan, Republic of Korea) with diameters varying from $(3.0 \mathrm{~mm}$ to3.8mm) and varying length from $(11,13 \mathrm{~mm})$.

The tapered design of the implant makes load distribution that may achieve excellent bone response, the conical hex connection between the implant and the abutment interface ensures hermetic sealing, the biological connection distributes the load to the fixture evenly, and therefore it helps to minimize micro-movement and marginal bone loss, double thread increase the initial stability, and the greater distance between the thread may promote early osseointegration

\section{II-Cholecalciferol and calcium}

Calcium D3F oral tablets used once daily after breakfast. (Arab company for pharmaceuticals and medicinal plants/EnshasElRaml -Sharkeya-Egypt/www.mepacopharma.net).Each tablet contains: Natural Calcium carbonates from oyster shell $1000 \mathrm{mg}$ Vit D3 $0.025 \mathrm{mg}$ (1000 I.U) Sodium Fluoride 0.25 mg.

\section{Methods}

\section{A-Preoperative phase}

All patients were evaluated by proper history taking and through clinical and radiographical examination

\section{Preoperative preparation}

Phase I therapy was carried out for all patients including scaling and gingival treatment.

i- Clinical examination of oral hygiene, gingival and periodontal health of the patient was carefully done.

\section{ii-Laboratory analysis:}

Through taking a blood sample to check kidney function (urea and creatinine) and calcium blood level for the study group.

\section{iii-Radiographic evaluation:}

Through Cone Beam Computed Tomography (CBCT) to show bone quality and quantity for ,selection of the right size implant for optimal support ,precision placement of implants in the bone, their relationto adjacent structures and to evaluate the condition of bone. (Fig. 1)

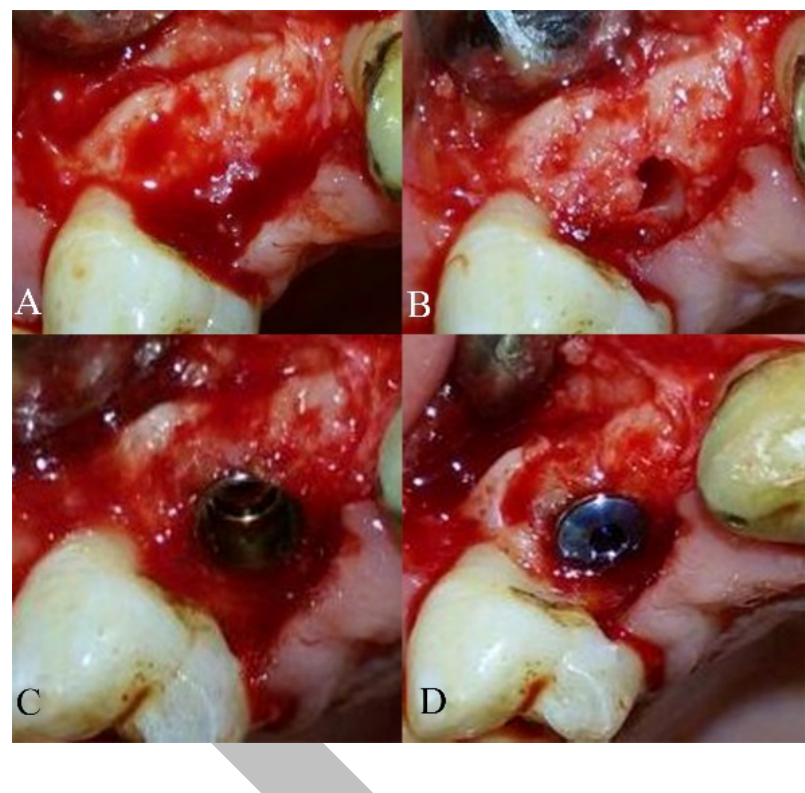

Figure 1: Steps of Implant placement.(fig1a.showing the site of implant after flap reflection),(fig1b,showing the site of the implant),(fig1c,showing the implant afterplacement),(fig1d,showing the implant cover screw).

\section{B- Surgical phase}

The operation was done with the patient under local anesthesia (Articaine HCL with epinephrine 1:100,000)(Ubistesin forte, 3M Deutschiand GmbH Carlstrabe 741453 Neuss, Germany).A crestal incision was started over the edentulous area over the ridge using Blade Barker N.o15.Drilling was carried out in the central part of the alveolar bone.The initial marking or preparation of the implant site was done with a pilot drill of $2.2 \mathrm{~mm}$, then widened using an intermediate drill and the final drill according to the diameter of the implant, the implant was then threaded into the bone using Ratchet, then the cover screw was placed, and the flap was sutured around the fixtures using 3/0 black silk suture.

\section{C-Postoperative phase}

- Postoperative instructions No pressure on the surgical site.

- Cold fomentation for the first 24 hours. Mouth wash on the next day.

- Avoid chewing solid food. Oral hygiene recommendation. - Sutures were removed one week after surgery.

\section{D-Postoperative medications}

All patients received:

i-Antibiotic tablets for 7 days, 1 tablet evey 12 hours (Amoxicillin 875+ clavulenic acid 125) (Augmentin 1 g,GlaxoSmithkline, Hungary).

ii-Analgesic: (50 mg diclofenac potassium): (Cataflam, Novartis Pharma, Cairo, Egypt) nonsteroidal antiinflammatory drugs for 5 days, 1 tablet every 8hours.

iii- Mouth wash, chlorohexidine HCL (0.12\%) (Hexitol, The Arab Drug Company, Cairo, A.R.E).

The study group received Combination of Cholecalciferol and calcium (calcium carbonate 1000mg+ VitD3 $0.025 \mathrm{mg}+$ sodium fluoride $0.25 \mathrm{mg}$ ) 1 tablet once daily for 8 months (CalciumD3F: Arab company for pharmaceuticals and medicinal plants/ EnshasElRaml -Sharkeya-Egypt).

\section{E-Postoperative follow up phase}

All patients were evaluated immediately postoperativelyand on intervals of $4 \& 8$ months, for presence of pain using Visual Analogue Scale (16)(VAS)as follows: 
$0=$ No pain

$1=$ Mild pain: It is easily tolerated.

$2=$ Moderate pain: It is causing discomfort but bearable.

$3=$ Severe pain: It is causing discomfort, hardly tolerated and unbearable. The presence of pain, tenderness, infection or swelling may indicate the presence of peri-implant disease and possible accelerated bone loss.

Implant mobility of the implant according to Mckinney and Koth (17), modified gingival index and papillary bleeding index (18).

All the implants involved in this study were radiographedby cone beam CT on $4 \& 8$ months to assess the marginal bone height and bonedensity around the implants using CBCT program (Fig. 2)Final prosthesis (porcelain fused to metal crown) wasplaced after four months.

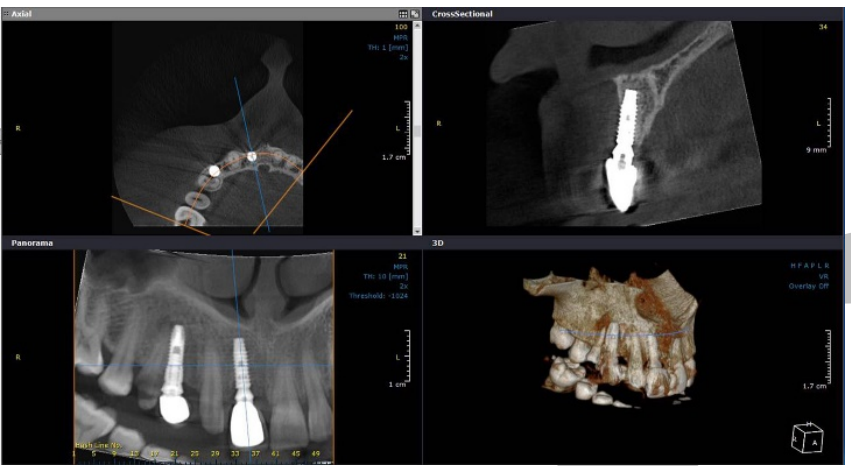

Figure 2: Cone beam CT X-ray.

\section{Statistical analysis}

The statistical analysis was performed to evaluate the bonedensity on intervals of 4 and 8 months. Data were fed to the computer and analyzed using Statistical Package for Social Sciences (SPSS/ version 18) software.

The statistical tests used as follow:

1-Mann Whitney test used for comparison between two independent groups with abnormally distributed data.

2- Likelihood ratio test (LRT) used to compare scores of two independent groups.

\section{RESULTS}

The present study has been conducted on 14 implants placed in maxillary anterior teeth for 14 post-menopausal female patients. The age ranges from 40 to 60 with the mean age range 55.

Seven implants were inserted in the maxillary central incisor with diameter $3.3 \mathrm{~mm}$ and length $11.8 \mathrm{~mm}$, four implant were inserted in the maxillary lateral incisor with diameter $3 \mathrm{~mm}$ and length $11 \mathrm{~mm}$ and three implants were inserted in the maxillary canine with diameter3.8 and length $13 \mathrm{~mm}$.

The operation was performed under local anesthesiausing surgical flap technique and the implant is placed, with no complications during the operation.

All patients had been examined periodically during thefollow-up period up to 8 months. Healing was uneventful inall cases with no post-operative complications. Otherclinical parameters had been recorded such as: Pain index,implant mobility.

\section{1)Pain, Tenderness, Infection and/or Swelling:}

After surgery, all patients experienced slight to moderate pain at the surgical site with mean pain severity 4 which disappeared completely after the 2nd and 3rd days and all patients experienced mild to moderate edema which also disappeared completely after two days The mean pain duration was $1.4 \pm 0.52$ and the Oedema percentage was $30 \%$ moderate to $70 \%$ mild. (Fig. 3 ).

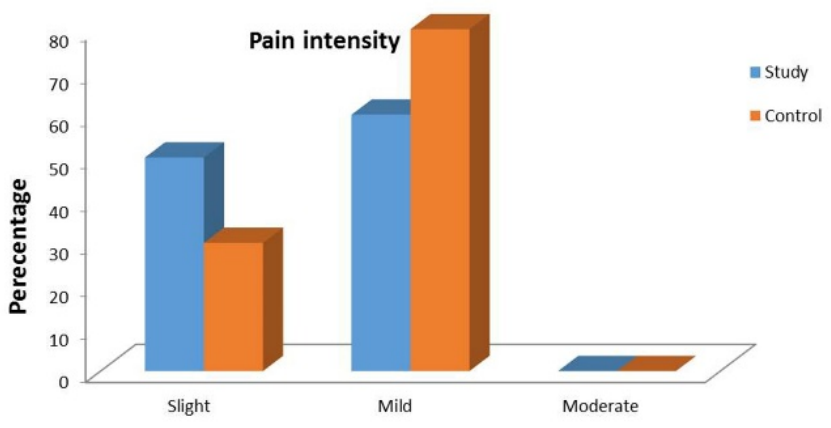

Figure 3: Comparison between the two studied groups according to Pain intensity.

\section{2) Implant mobility:}

Mobility was recorded according to Mickinney and Koth (17). All over the evaluation period, none of implant showed any signs of mobility (i.e. mobility score was 0 ).

\section{3) Modified gingival index:}

No signs of gingival inflammation were observed in all patients all over the evaluation period (i.e. modified gingival index score was 0 ).

4) Papillary bleeding index (18):

On the fourth month: The difference in (PBI) readings between the two groups was found to be statistically insignificant $(\mathrm{LR}=6.534, \mathrm{p}=0.386)$.

On the eighth month: The difference in (PBI) readings between the two groups was found to be statistically insignificant $(\mathrm{LR}=2.7773, \mathrm{p}=0.428)$ (Fig. 4, Table 1).

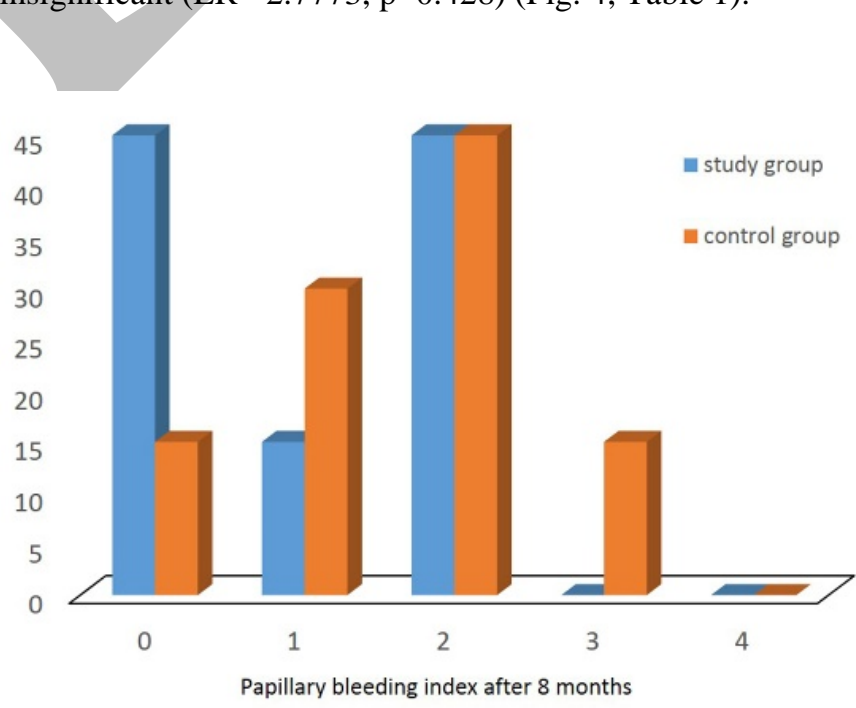

Figure 4: Comparison between the study group and the control group according to the papillary bleeding index after 8 months. 
Table 1: Comparison between the two studied groups according to papillary bleeding index.

\begin{tabular}{|c|c|c|c|c|c|}
\hline $\begin{array}{c}\text { Papillary Bleeding } \\
\text { index }\end{array}$ & \multicolumn{2}{|c|}{$\begin{array}{c}\text { Study } \\
\text { group }(n=7)\end{array}$} & \multicolumn{2}{|c|}{$\begin{array}{c}\text { Control group } \\
(\mathbf{n}=7)\end{array}$} & \multirow[t]{2}{*}{$\begin{array}{c}\text { Test of } \\
\text { significance } \\
\text { (P value)* }\end{array}$} \\
\hline & & & & & \\
\hline - 0 & $\mathbf{0}$ & $0 \%$ & $\mathbf{0}$ & 0\% & \multirow{5}{*}{$\begin{array}{c}\mathrm{LR}=6.534 \\
(0.386)\end{array}$} \\
\hline - 1 & 3 & $\begin{array}{c}42.9 \\
\%\end{array}$ & 1 & $14.3 \%$ & \\
\hline - 2 & 2 & $\begin{array}{c}28.6 \\
\%\end{array}$ & 5 & $71.4 \%$ & \\
\hline - 3 & 2 & $\begin{array}{c}28.6 \\
\%\end{array}$ & $\mathbf{0}$ & 0\% & \\
\hline - 4 & $\mathbf{0}$ & 0\% & 1 & $14.3 \%$ & \\
\hline \multicolumn{6}{|l|}{$\begin{array}{c}\text { Papillary bleeding } \\
\text { after } 6 \text { months }\end{array}$} \\
\hline - 0 & 3 & $\begin{array}{c}42.9 \\
\%\end{array}$ & 1 & $14.3 \%$ & \multirow{5}{*}{$\begin{array}{c}\mathrm{LR}=2.773 \\
(\mathbf{0 . 4 2 8 )}\end{array}$} \\
\hline - 1 & 1 & $\begin{array}{c}14.3 \\
\%\end{array}$ & 2 & $28.6 \%$ & \\
\hline - 2 & 3 & $\begin{array}{c}42.9 \\
\%\end{array}$ & 3 & $42.9 \%$ & \\
\hline - 3 & $\mathbf{0}$ & $0 \%$ & 1 & $14.3 \%$ & \\
\hline - 4 & $\mathbf{0}$ & $0 \%$ & $\mathbf{0}$ & 0\% & \\
\hline
\end{tabular}

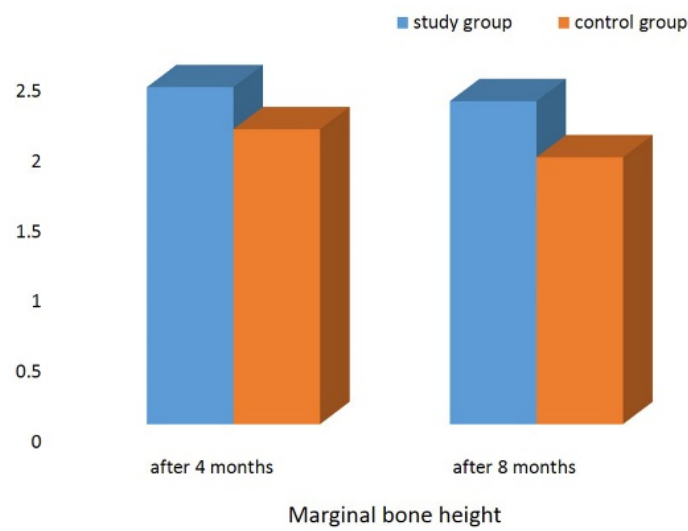

Figure 5: Comparison between the study group and the control group according to the marginal bone height.

Table 2: Comparison between the study group and the control group according to the marginal bone height.

\begin{tabular}{|c|c|c|c|}
\hline $\begin{array}{l}\text { Marginal bone } \\
\text { height (mm) }\end{array}$ & $\begin{array}{c}\text { Control } \\
\text { group } \\
(\mathbf{n}=7)\end{array}$ & $\begin{array}{l}\text { Study group } \\
\qquad(\mathrm{n}=7)\end{array}$ & \\
\hline \multicolumn{3}{|l|}{ After 4 months } & \multirow{3}{*}{$\begin{array}{c}Z=1.431 \\
(0.19)\end{array}$} \\
\hline Min-Max & $1.50-2.60$ & $2.00-3.00$ & \\
\hline Mean \pm SD & $2.18 \pm 0.38$ & $2.48 \pm 0.30$ & \\
\hline \multicolumn{3}{|l|}{ After 8 months } & \multirow{3}{*}{$\begin{array}{c}Z=2.014 \\
(0.53)\end{array}$} \\
\hline Min-Max & $1.40-2.30$ & $2.00-2.80$ & \\
\hline Mean \pm SD & $1.98 \pm 0.30$ & $2.32 \pm 0.28$ & \\
\hline
\end{tabular}

Radiographic evaluation Marginal bone height (Fig. 5, Table 2)

For comparison of marginal bone level between the two Groups

Data were collected regarding the marginal bone height at the mesial and distal aspects of all implants.
The marginal bone loss increase steadily from immediate post-operative $(3.00 \pm 0.38 \mathrm{~mm})$ in the two groups to decrease after that.

\section{At the fourth months}

Mean marginal bone level for control group was (2.18 $\pm 0.38 \mathrm{~mm})$.

Mean marginal bone level for study group was (2.48 $\pm 0.30 \mathrm{~mm})$.

\section{At the eighth months}

Mean marginal bone level for control group was $(1.98 \pm 0.30 \mathrm{~mm})$.

Mean marginal bone level for study group was (2.32 $\pm 0.28 \mathrm{~mm})$.

This difference in marginal bone level values between the two groups was found to be statistically insignificant ( $\mathrm{Z}=2.014$, p-value=0.53).

Evaluation of bone density around the implant (Fig. 6, Table 3)

Densitometric analysis was performed around dental implants on CBCT image at intervals of immediate, 4th month and 8th month postoperatively using the "SICAT GALILEOS Implant” software.

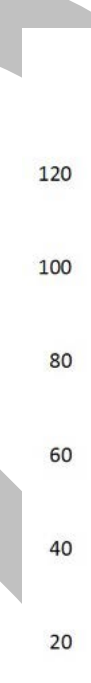

0

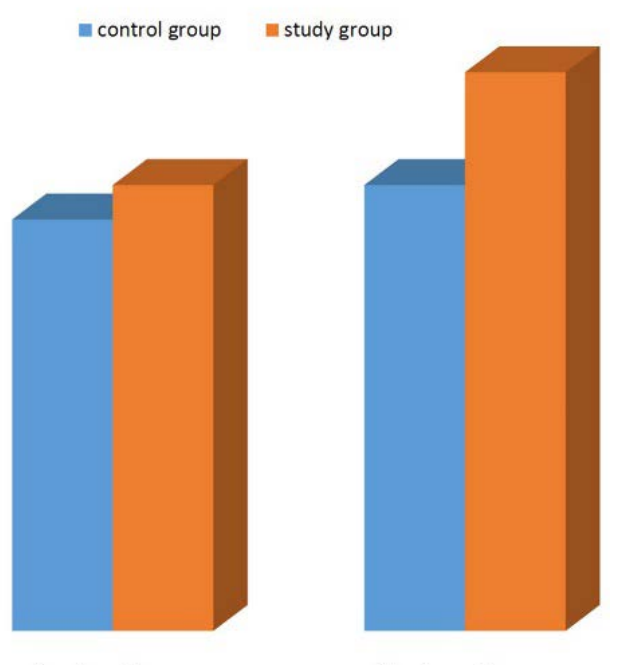

after 4 months after 8 months
Figure 6: Comparison between the study group and the control group according to the bone density.

Table 3: Comparison between the study group and the control group according to the Bone density.

\begin{tabular}{|c|c|c|c|}
\hline $\begin{array}{c}\text { Bone density } \\
\text { (pixel) }\end{array}$ & $\begin{array}{c}\text { Control group } \\
(n=7)\end{array}$ & $\begin{array}{c}\text { Study } \\
\text { group } \\
(n=7)\end{array}$ & $\begin{array}{c}\text { Test of } \\
\text { significance } \\
\text { (p value)* }\end{array}$ \\
\hline \multicolumn{3}{|l|}{4 months } & \multirow{3}{*}{$\begin{array}{c}\mathrm{Z}=0.256 \\
(0.312)\end{array}$} \\
\hline Min-Max & $83.25-184.00$ & $\begin{array}{l}85.14- \\
172.12\end{array}$ & \\
\hline Mean \pm SD & $87.65 \pm 27.36$ & $\begin{array}{c}90.22 \pm \\
35.20\end{array}$ & \\
\hline \multicolumn{3}{|l|}{8 months } & \multirow{3}{*}{$\begin{array}{l}\mathrm{Z}=0.575 \\
(0.008)^{*}\end{array}$} \\
\hline Min-Max & $87.25-180.16$ & $\begin{array}{l}93.15- \\
204.13\end{array}$ & \\
\hline Mean \pm SD & $90.84 \pm 41.6$ & $\begin{array}{c}120.8 \pm \\
39.53\end{array}$ & \\
\hline
\end{tabular}




\section{Immediate post-operative}

Mean bone density value for control group was (82.23 27.36) pixel.

Mean bone density value for study group was (85.23 \pm 39.03) pixel.

\section{At the fourth months}

Mean bone density value for control group was (87.65 \pm 49.51$)$ pixel.

Mean bone density value for study group was $(90.22 \pm 35.20)$ pixel.

This difference in bone density values was found between the two groups to be statistically insignificant $(\mathrm{Z}=0.256, \mathrm{p}=$ 0.0312 )

\section{At the eighth months}

Mean bone density value for control group was (90.84 \pm 41.6$)$ pixel.Mean bone density value for study group was (120.8 \pm 39.53$)$ pixel.

This difference in bone density values was found to be statistically significant $(\mathrm{Z}=0.575, \mathrm{p}=0.008)$.

\section{DISCUSSION}

The successful outcome of any implant procedure depends on a series of patient-related and procedure-dependent parameters, including general health conditions, biocompatibility of the implant material, the microscopic and macroscopic nature of the implant surface, the surgical procedure and the quality and quantity of the local bone(19).

The objectives of the present study was to evaluate the effect of systemic Vitamin D and Calcium on postmenopausal female osseointegration of delayed endoosseous dental implants. The study was performed on 14 postmenopausal females, Selected form the outpatient clinic of the Oral and Maxillofacial Surgery Department, Alexandria University. Their ages ranged from (40 - 60 years).

The selected patients were free from any systemic diseases or a condition that may complicate the surgical procedure or the healing process of the implant this was following Bornstein et al., (20) in 2009 where they reviewed whether systemic diseases with/without systemic medication increase the risk of implant failure and therefore diminish success and survival rates of dental implants.Recent studies demonstrated that uncontrolled diabetes may lead to high incidence of implant failure. This could be attributed to the fact that normal metabolism of phosphorus and calcium is essential for bone mineralization \& remodeling and is affected by hyperglycemia. The latter alters the response of parathyroid hormone. In addition, diabetes mellitus inhibits osteooblastic differentiation, impairs circulation and reduces chemotaxis and phagocytosis of neutrophils thus increasing the susceptibility for infection (21).

Regarding the surgical procedure, all included patients were subjected to delicate surgery using delayed implant placement protocol. The use of sharp drills mounted on a low speed, high torque hand piece during the preparation of the implant bed. Drilling was performed under profuse irrigation using sterile saline solution drills were designed to allow the cooling to pass to the bottom of the implant site during preparation.

In the present study, primary wound closure of the implant site was considered an important factor to reduce the possibility of postoperative infection, inflammation and also to prevent epithelial down growth during the healing period (22).

As reported by Al-Sabbagh et al in 2015 (23) that the clinical signs of peri-implant infection are considered to be associated with implant failures. The lack of osseointegration is generally distinguished by implant mobility and radiological radiolucency. Here, the implant is considered to be failed. Failure of this case could be attributed to lack of oral hygiene maintenance by the patient in spite of the instructions given to her.

A two - stage implantation procedure was chosen to provide prolonged direct bone - implant interface before implant exposure to functional load thus promoting and enhancing the process of osseointegration to its optimal aspects $(12,24-27)$.

Vitamin D3 and calcium supplement were also given to the study group orally during the post-operative period(28, 29).

Regarding the implant mobility, no detectable clinical mobility of anyone of the used implants was detected throughout the evaluation period. This was confirmed by radiographic evaluation that revealed the absence of periimplant radiolucency. This indicates proper osseointegration of all implants. The absence of implant mobility is considered to be the most important criteria for implant success (30). In this study assessment of the soft tissues was completed using gingival index(31). There was anon significant reduction of the mean gingival index values for both implants placed in both groups. These results were attributed to the oral hygiene instructions followed properly by the patients and good contouring of the crown with the gingival for self-cleansing maintenance heading to reduction of inflammation and rapid and favorable healing process $(33,34)$. This finding was in accordance with Joly et al in 2003(33). In the present study radiographic evaluation for measuring marginal bone height around the implant was carried out using CBCT which was taken after 4 and 8 months follow up period.

The mean marginal bone loss showed statistically significant increase during the first 4 months following implant placement in both groups. However, this increase in the marginal bone loss was found to be statistically nonsignificant from 4 to 8 months indicating stabilization of marginal bone levels. This initial bone loss around dental implants was in agreement with Shimpuku et al in 2003 (34).

In the present study the radiological assessment showed that the mean bone density was higher in the study group than in the control group and changes between the two groups were statistically significant it was detectable 4 and 8 months after implant placement.These results were in agreement with the results of Yunus (35) in 2011. In his study, 30 patients were evaluated using CT to determine the changes of jaw bone density around the dental implant after placement. The study concluded that bone density around dental implant was increased after placement. The increased rate of bone density could be determined by the quality of jaw bone before implant placement. The bone deposition and tendency to increase with time indicating constant bone deposition and mineralization around the implant fixture.

Concerning to the effect of vitamin D in study group in the present work, the observation are coincidence with Zhou et al in 2004 (36). WHO advocated that, it is important to know the effect of vitamin D on implant osseointegration. 
This study indicated that vitamin D increased peri-implant bone density, and enhanced implant fixation. Thus, these findings suggest that vitamin $\mathrm{D}$ promotes implant osseointegration in osteoporotic bone(37).The increase of peri-implant bone density and improvement of bone architecture ultimately led to the enhancement of implant osseointegration and fixation. Thus, these results suggested the protective effect of vitamin $\mathrm{D}$ on bone healing after implant insertion. Although increased bone density and improved bone microarchitecture by vitamin $\mathrm{D}$ were observed in this study, factors contributing to this effect were still not clarified, namely the increased bone density might be a result of inhibited bone resorption.

\section{CONCLUSION}

Cholecalciferol (vitamin D3) and Calcium has systemic effects on accelerating bone formation around titanium implants.

\section{CONFLICT OF INTEREST}

The authors declare that they have no conflicts of interest.

\section{REFERENCES}

1. lsaksson S. Evaluation of three bone grafting techniques for severely resorbed maxilla in conjunction with immediate endosseous implants. Int J Oral Maxillofac Implants. 1994;9:679-88.

2. Covani U, Bortolaia C, Barone A, Sbordone L. Buccolingual crestal bone changes after immediate and delayed placement. J Periodontol. 2004;75:1605-12.

3. Ogismo M, Tabata T, Lee RR, Borgese D. Delay method of implantation enhances implant-bone binding: A comparison with the conventional method. Int J Oral Maxillofac Implants. 1995;10:415-20.

4. Marco F, Milena F, Gianluca G, Vittoria O. Periimplant osteogenesis in health and osteoporosis. Micron. 2005;36:630-44.

5. Linder L, Obrant K, Boivin G. Osseointegration of metallic implants. II. Transmission electron microscopy in the rabbit. ActaOrthop Scand. 1989;60:135-9.

6. Soballe K. Hydroxyapatite ceramic coating for bone implant fixation. Mechanical and histological studies in dogs. ActaOrthopScand Suppl. 1993;255:1-58.

7. Khan SN, Cammisa FP Jr, Sandhu HS, Diwan AD, Girardi FP, Lane JM. The biology of bone grafting. J Am AcadOrthop Surg. 2005;13:77-86.

8. Younger EM, Chapman MW. Morbidity at bone graft donor sites. J Orthop Trauma. 1989;3:192-5.

9. Eberhardt C, Habermann B, Müller S, Schwarz M, Bauss F, Kurth AH. The bisphosphonate ibandronate accelerates osseointegration of hydroxyapatite-coated cementless implants in an animal model. J Orthop Sci. 2007;12:61-6.

10. Başarir K, Erdemli B, Can A, Erdemli E, Zeyrek T. Osseointegration in arthroplasty: can simvastatin promote bone response to implants? IntOrthop. 2009;33:855-9.

11. Viljakainen HT, Natri AM, Kärkkäinen M, Huttunen MM, Palssa A, Jakobsen J, et al. A positive dose-response effect of vitamin D supplementation on site-specific bone mineral augmentation in adolescent girls: a double-blinded randomized placebo-controlled 1-year intervention. J Bone Miner Res. 2006;21:836-44.

12. Schedlich LJ, Muthukaruppan A, O'Han MK, Baxter RC. Insulin-like growth factor binding protein-5 interacts with the vitamin $\mathrm{D}$ receptor and modulates the vitamin $\mathrm{D}$ response in osteoblasts. MolEndocrinol. 2007;21:2378-90.

13. Shiraishi A, Higashi S, Ohkawa H, Kubodera N, Hirasawa $\mathrm{T}$, Ezawa I, et al. The advantage of alfacalcidol over vitamin $\mathrm{D}$ in the treatment of osteoporosis. Calcif Tissue Int. 1999;65:311-6.

14. Sairanen S, Kärkkäinen M, Tähtelä R, Laitinen K, Mäkelä $\mathrm{P}$, Lamberg-Allardt C, et al. Bone mass and markers of bone and calcium metabolism in postmenopausal women treated with 1,25-dihydroxyvitamin D (calcitriol) for four years. Calcif Tissue Int. 2000;67:122-7.

15. Macdonald HM, Wood AD, Aucott LS, Black AJ, Fraser WD, Mavroeidi A, et al. Hip bone loss is attenuated with 1000 IU but not 400 IU daily vitamin D3: a 1 year doubleblind RCT in postmenopausal women. J Bone Miner Res. 2013;28:2202-13.

16. Pasqualini D, Cocero N, Castella A, Mela L. Primary and secondary closure of the surgical wound removal of the impacted mandibular 3rd molar: a comparative study. Int J MaxillofacSurg 2005;34:52-7.

17. Mckinney R, Koth D, Steflik D. Clinical standards for dental implant. In: Clark JW (ed). Clinical dentistry. Harperstwon: Harper and Row, 1998;1-11.

18. Muhlemann HR. Physiology and chemical mediators of gingival health. J Prev Dent 1977; 4:6-20.

19. Beer A, Gahleitner A, Holm A, Tschabitscher M, HomolkaP.Corelation of insertion torques with bone mineral density from dental quantitative CT in the mandible.Clin Oral Implants Res 2003; 14:616-20.

20. Bornstein MM, Cionca N, Mombelli A. Systemic conditions and treatments as risks for implant therapy. Int J Oral Maxillofac Implants 2009; 24: 12-27.

21. Leonhardt A, Dahlen G, Renvert S. Five- year clinical, microbiological and radiological outcome following treatment of peri- implantitis in man. J Periodontol 2003; 74: 1415-22.

22. Elsubeihi E, Zarb G. Implant Prosthodontics in Medically Challenged Patients. J Can Dent Assoc.2002; 68(2): 103-8.

23. Al-Sabbagh M, Bhavsar I. Key local and surgical factors related to implant failure. Dent Clin North Am 2015; 59: 123.

24. Becker W, Becker B. Guided tissue regeneration for implants placed into extraction socket and for implant dehiscence: Surgical techniques and case reports. Int J PeriodontRestor Dent. 1990;10:376-91.

25. Elsubeihi E, Zarb G. Implant Prosthodontics in Medically Challenged Patients. J Can Dent Assoc. 2002;68:103-8.

26. Mori H, Manabe M, Kurachi Y, Nagume M. Osseointegration of dental implants in rabbits with low mineral density. J Oral Maxillofac Surg. 1997;55:351-61.

27. Brånemark PI. Osseointegration and its experimental studies. J Prosthet Dent. 1983;50:399-410.

28. Ciancio S, Lauciello F, Shibly O, Vitello M, Mather M. The effect of an antiseptic mouthrinse on implant maintenance: plaque and peri implant gingival tissues. J Periodontol. 1995;66(11):962-5.

29. Beilker T, Flemmig F. Implant in the medically compermised patients. Crit Rev Oral Biol Med. 2003;14:305-16.

30. Dao T, Anderson J, Zarb G. Is osteoporosis a risk factor for osseointegration of dental implants? Int J Oral Maxillofac Implants. 1993;8:137-44. 
31. Porter J, Von Fraunhofer J. Success or failure of dental implants? A literature review with treatment considerations. General Dent. 2005;53:423-32.

32. Loe H, Silness J. The Gingival Index, the Plaque Index and the Retention Index system. J Periodontol. 1967;38:610.

33. Joly J, de Lima A, Da Silva R. Clinical and radiographic evaluation of soft and hard tissue changes around implants; A pilot study. J Periodontol. 2003;74:1097-103.

34. Shimpuku H, Nosaka Y, Kawamura T, Tachi Y, Shinohara M, Ohura K. Genetic polymorphism of interleukin-1 gene and early marginal bone loss around endosseous dental implants. Clin Oral Implants Res. 2003;14:423-9.

35. Yunus B. Assessment of the increased calcification of the jaw bone with CT-Scan after dental implantplacement. Imaging Sci Dent 2011; 41: 59-62

36. Zhou XQ, Hu J, Du ZJ, Yang JH, Liu M, Li XM. Oestrogen replacement therapy promotes bone healing around dental implants in osteoporotic rats. Int J Oral Maxillofac Surg. 2004;33:279-285.

37. Fulker K.Update on bone density measurement. Rheum Dis Clin North Am. 2001;27:81-99.

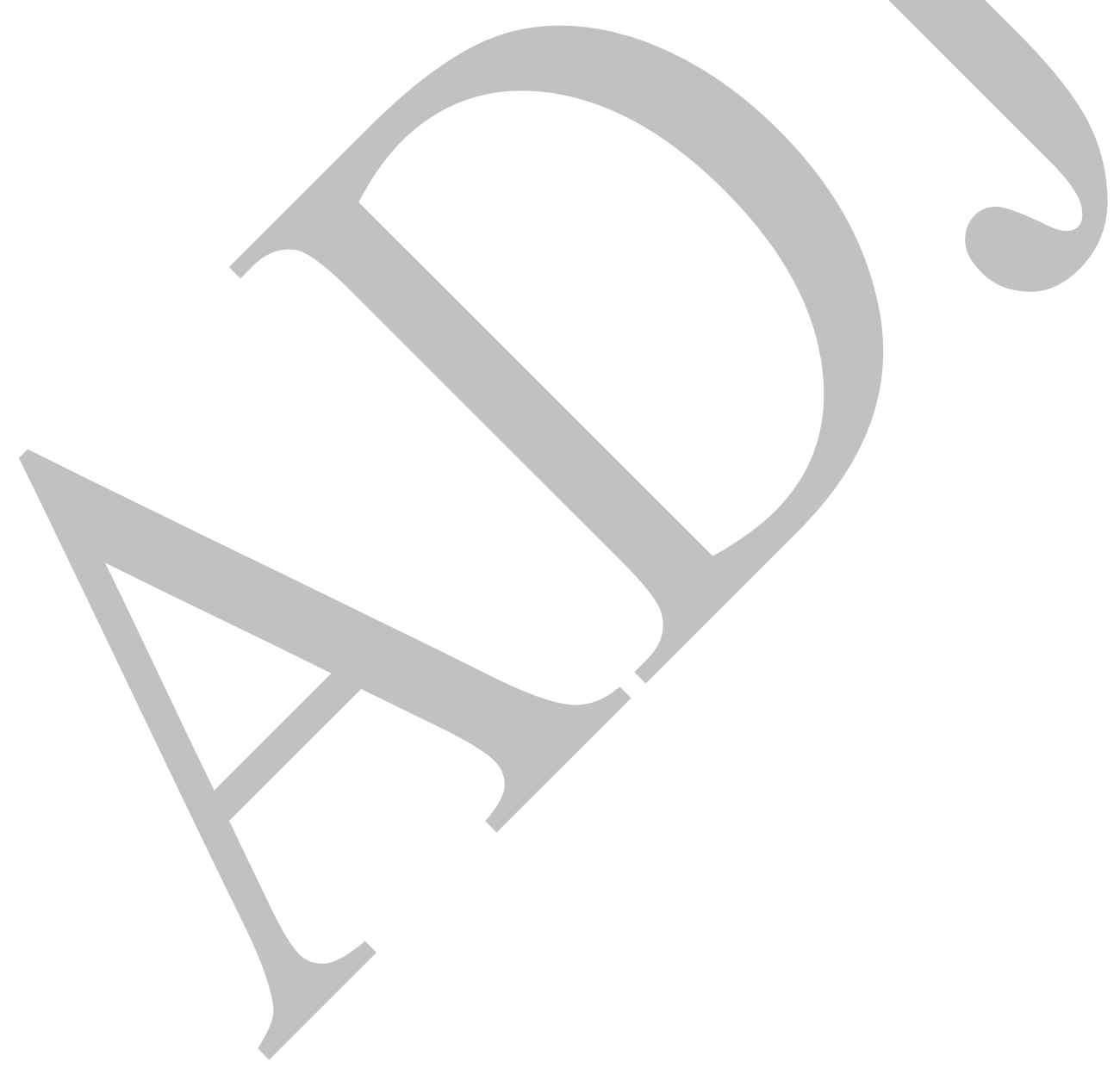

